The response of the HMX-based material PBXN-9 to thermal insults: thermal decomposition kinetics and morphological changes

E. A. Glascoe, P. C. Hsu, H. K. Springer, M. R. DeHaven, N. Tan, H. C. Turner

December 13, 2010

Thermochimica Acta 
This document was prepared as an account of work sponsored by an agency of the United States government. Neither the United States government nor Lawrence Livermore National Security, LLC, nor any of their employees makes any warranty, expressed or implied, or assumes any legal liability or responsibility for the accuracy, completeness, or usefulness of any information, apparatus, product, or process disclosed, or represents that its use would not infringe privately owned rights. Reference herein to any specific commercial product, process, or service by trade name, trademark, manufacturer, or otherwise does not necessarily constitute or imply its endorsement, recommendation, or favoring by the United States government or Lawrence Livermore National Security, LLC. The views and opinions of authors expressed herein do not necessarily state or reflect those of the United States government or Lawrence Livermore National Security, LLC, and shall not be used for advertising or product endorsement purposes. 


\title{
The response of the HMX-based material PBXN-9 to thermal insults: thermal decomposition kinetics and morphological changes
}

\author{
Elizabeth A. Glascoe ${ }^{a^{*}}$, Peter C. Hsu ${ }^{a}$, H. Keo Springer ${ }^{a}$, Martin R. DeHaven ${ }^{a}$, Noel Tan ${ }^{a}$, Heidi C. Turner ${ }^{a}$ \\ ${ }^{a}$ Energetic Materials Center, Lawrence Livermore National Laboratory, 7000 East Avenue, Livermore, CA 94550 \\ *Corresponding Author. Tel.: +1 925424 5194; fax: +1 925424 3281; E-mail address: glascoe2@1lnl.gov
}

\begin{abstract}
PBXN-9, an HMX-formulation, is thermally damaged and thermally decomposed in order to determine the morphological changes and decomposition kinetics that occur in the material after mild to moderate heating. The material and its constituents were decomposed using standard thermal analysis techniques (DSC and TGA) and the decomposition kinetics are reported using different kinetic models. Pressed parts and prill were thermally damaged, i.e. heated to temperatures that resulted in material changes but did not result in significant decomposition or explosion, and analyzed. In general, the thermally damaged samples showed a significant increase in porosity and decrease in density and a small amount of weight loss. These PBXN-9 samples appear to sustain more thermal damage than similar HMX-Viton A formulations and the most likely reasons are the decomposition/evaporation of a volatile plasticizer and a polymorphic transition of the $\operatorname{HMX}$ from $\beta$ to $\delta$ phase.
\end{abstract}

\section{Keywords}

Thermal damage, thermal decomposition, kinetics, HMX, PBXN-9

\section{Introduction}

A thorough understanding of the response of energetic materials to heat is of broad interest to the explosives and propellants communities. The development of safe handling and storage methods requires a detailed understanding of how a material changes when exposed to heat. Mild heating of an explosive may produce morphological and/or compositional changes that may alter the microstructure and increase material surface area due to the introduction of voids and pores. These changes can affect the material properties such as sensitivity, safety, and performance; hence handling and reusing a damaged explosive requires careful consideration. A prior knowledge of how the material behaves when heated would allow workers to make more informed decisions about how to deal with a thermally damaged material. In addition, a basic understanding of thermally induced changes assists in the interpretation of more complex experiments such as deflagration, shock and/or impact initiation experiments, and thermal explosions. Finally, quantitative characterization of materials after mild heating and development of decomposition kinetic models provides the data necessary to develop and/or parameterize computational models used to predict phenomenon such as thermal explosion, shock or impact initiation, sample deflagration, etc.

The kinetics and mechanisms of thermal decomposition of energetic materials are particularly important to the study of thermal explosions (e.g. cook-off). A material might explode if it is exposed to a stimulus sufficient to initiate significant material decomposition, typically the stimulus is heat. In most slow cook-off scenarios, the first step is molecular-level decomposition via a mechanism that begins with one or more endothermic and/or exothermic reactions. The decomposition is accelerated by autocatalytic chemical reactions and the energy released due to exothermic reactions. Eventually the material begins to deflagrate (i.e. burn) and consumption of the material accelerates. Some materials shift from deflagration to detonation (DDT), yet even materials that do not undergo DDT can react quite violently, as has been observed in one-dimensional-time-to-explosion (ODTX) and scaledthermal-explosion (STEX) experiments $[1,2]$.

The energetic material HMX (octahydro-1,3,5,7-tetranitro-1,3,5,7-tetrazocine) is a common molecule used in a variety of different explosives; consequently, there is a considerable volume of literature investigating the response of HMX based materials to heat [3-8]. At approximately $160{ }^{\circ} \mathrm{C}$, HMX experiences a polymorphic transition, from the $\beta$ - to the $\delta$-polymorph [8]. Because the $\delta$-polymorph is approximately $7 \%$ larger in volume the explosive charge may experience irreversible volume expansion and a significant increase in sample porosity due to irreversible rearrangement of the crystal-binder packing [9]. These changes in morphology can change the performance of the

LLNL-JRNL-463953

Released for public Audience

Published in Thermochimica Acta, 515 (2011) 58-66. 
explosive charge. Previous studies demonstrate that both gas permeabilities and burn rates of the damaged LX-04 samples (85\% HMX, 15\% Viton A) increased by several orders of magnitude [7, 10]. Urtiew et. al reported that heated LX-04 was more sensitive to shock initiation at high temperatures [11]. Hsu et al. reported that both detonation velocity and detonation energy density of thermally damaged LX-04 were significantly lower than those of pristine high-density LX-04 [12].

The material PBXN-9 consists of the energetic material HMX, the plasticizer dioctyl adipate (DOA), and a polyacrylate elastomer binder (HYTEMP 4454). HMX based materials have been studied extensively, however, many of the studies have focused on materials with inert binders (i.e. Viton A, hereafter referred to simply as Viton) $[7,10]$. In contrast to these previous studies, PBXN-9 has a low boiling point plasticizer. The volatility of the plasticizer causes the material to undergo significant morphological changes upon heating to temperatures that do not affect the HMX.

Here we report on the kinetics of PBXN-9 decomposition, based on conventional thermal analysis techniques and kinetic analysis methods. We also explore the morphological changes in the material (e.g. porosity, gas permeability and extent of cracking) after heating to moderate temperatures $\left(\mathrm{T} \leq 180{ }^{\circ} \mathrm{C}\right)$. These PBXN-9 results are compared to similar HMX based materials in order to gain a more complete and fundamental understanding of the response of HMX based materials to thermal insults.

\section{Experimental}

\subsection{Sample}

PBXN-9 was used as received, in powder/prill form, from BAE systems (Lot number BAE06F08-064). The formulation described in Table 1 was based on the certificate of analysis for this specific lot number. Samples of Hytemp 4454 from Zeon were used as received for the neat binder studies. Samples of Hytemp + DOA (i.e. the binder + plasticizer) were prepared via minor modifications of the PBXN-9 formulation procedure (NSWC TR 86334). Briefly, $0.950 \mathrm{~g}$ Hytemp 4454 was combined with $2.6515 \mathrm{~g}$ DOA and $8.40 \mathrm{~g}$ of ethyl acetate. This mixture was stirred for 17 hours allowing for integration of the DOA into the swollen Hytemp. After 17 hours the solution appeared viscous and uniform with no visible solid chunks of Hytemp present. The solution was poured into a small dish and the ethyl acetate was removed via slow evaporation at ambient temperature and $60{ }^{\circ} \mathrm{C}$.

Table 1.Weight percent distribution of samples.

\begin{tabular}{|l|c|c|c|}
\hline Sample Name & $\begin{array}{c}\text { Wt \% } \\
\text { Hytemp } \\
4454\end{array}$ & $\begin{array}{c}\text { Wt \% DOA } \\
\text { (Dioctyl } \\
\text { adipate) }\end{array}$ & $\begin{array}{c}\text { Wt \% } \\
\text { HMX }\end{array}$ \\
\hline PBXN-9 & 1.9 & 5.3 & 92.8 \\
\hline $\begin{array}{l}\text { Binder \& Plasticizer } \\
\text { (Hytemp + DOA) }\end{array}$ & 26.4 & 73.6 & \\
\hline Hytemp 4454 (neat) & 100 & 100 & \\
\hline DOA (neat) & & & \\
\hline
\end{tabular}

\subsection{Thermal Decomposition Experiments}

In order to better understand the decomposition processes in PBXN-9, a thermal decomposition study of the explosive and its constituent materials was undertaken. Thermal decomposition experiments were performed on four different samples: PBXN-9 prill/powder, neat binder (hereafter referred to as 'Hytemp'), neat plasticizer (i.e. dioctyl adipate, or DOA), and the mixture of binder and plasticizer (hereafter referred to as 'Hytemp + DOA'). Sample formulations are described in Table 1. Differential scanning calorimetry (DSC) experiments were carried out on a TA-instruments 2920 or a TA-instruments Q2000. Simultaneous differential thermal and gravimetric measurements (hereafter referred to as simply thermogravimetric or TGA experiments) were carried out on a TA-instruments 2960 or a TA-instruments Q600.

Three different pan types were used for the thermal decomposition experiments. In the DSC experiments the aluminum pans were either hermetically sealed or contained a pinhole in the top, in the TGA experiments the pans were open (i.e. lid free, alumina pan) and allow for free exchange of the sample gases with the environment, either nitrogen or air. The hermetically sealed pans prevent exchange of gases between the environment and the pan, hence 
the sample may experience some increase in pressure as it decomposes and generates product gases. Because these pans were sealed in air (i.e. on the bench-top) there is trapped oxygen inside the hermetically sealed pan. The pinhole pans are sealed but contain a small hole, ca. $35 \mu \mathrm{m}$, in the top which allows the pan to slowly exchange gases with the environment and maintain a constant pressure with its surroundings.

Thermogravimetric experiments were performed in two different environments: ultrazero air, which is a mixture of gases meant to simulate normal air, and gaseous nitrogen. Unless otherwise specified, all experiments performed and discussed here used ultrazero air.

Multiple heating rates were used for analyzing the kinetics of decomposition. In the case of neat Hytemp, samples were run at $3,5,10$, and $20^{\circ} \mathrm{C} / \mathrm{min}$ in duplicate for all samples and triplicate for the $3{ }^{\circ} \mathrm{C} / \mathrm{min}$. Neat DOA was run at $5,10,20$ and $40^{\circ} \mathrm{C} / \mathrm{min}$ in duplicate for all samples except the $5^{\circ} \mathrm{C} / \mathrm{min}$ which was only run once due to constrains on laboratory equipment availability at the time. The mixture of Hytemp + DOA was only run at 10 and $20^{\circ} \mathrm{C} / \mathrm{min}$, both in duplicate; this limited number of heating rates was chosen as the kinetic analysis was intended as a simple and quick means of exploring whether the Hytemp affects the DOA kinetics. Finally, PBXN-9 was run at $0.25,0.5$, and $2{ }^{\circ} \mathrm{C} / \mathrm{min}$, all in duplicate. These much slower heating rates for PBXN-9 were chosen because the rapid decomposition of HMX makes faster heating rate data (e.g. $4^{\circ} \mathrm{C} / \mathrm{min}$ or higher) difficult to interpret and too fast to extract meaningful kinetic parameters.

\subsection{Morphology Analysis Methods after Thermal Damage}

The thermal damage of PBXN-9 was induced by heating pressed and prill samples in an unconfined/isobaric environment using techniques described in the literature [13]. The oven and samples were ramped to $180{ }^{\circ} \mathrm{C}$ at a rate of $3{ }^{\circ} \mathrm{C} / \mathrm{min}$, and held for 3 hours. The samples were then cooled to room temperatures (average cooling rate of 1 ${ }^{\circ} \mathrm{C} / \mathrm{min}$ ) and characterized. Pristine and thermally damaged samples were examined using an optical microscope (Carl Zeiss Axioskope 40 pol/40A pol Polarizing microscope) and a scanning electron microscope (SEM) (LEO 438 VP Scanning Electron Microscope). Sample densities were measured using a gas pycnometer (AccuPyc 1330; nitrogen gas); details of the procedure are published [7]. The gas permeability measurements were collected using a gas diffusion permeameter (Porous Materials, Inc.; nitrogen gas). The permeameter is capable of measuring at ambient or elevated temperatures; hence, samples were measured at multiple temperatures, in situ, and compared to ambient temperature measurements of pristine PBXN-9 samples that were pressed to known densities.

\subsection{Kinetic Models}

Multiple kinetic models were used to fit the thermogravimetric data; they include the isoconversional analysis method, the ${ }^{\text {th }}$-order Arrhenius model, and the extended-Prout-Tompkins model. Briefly, in all three methods the rate equation for fraction reacted begins with:

$$
\frac{d \alpha}{d t}=k f(\alpha)=A e^{-E / R T} f(\alpha)
$$

where $\alpha$ is fraction reacted (0-1), $t$ is time, $k$ is the Arrhenius rate constant, $A$ is the pre-exponential factor, $E$ is the activation energy, $R$ is the gas constant, $T$ is temperature, and $f(\alpha)$ is the reaction model. In the Friedman isoconversional method,[14] equation (1) is rearranged to the following:

$$
\ln \left(\frac{d \alpha}{d t_{\alpha}}\right)=\frac{-E_{\alpha}}{R T_{\alpha}}+\ln \left[A_{\alpha} f(\alpha)\right]
$$

By plotting $\ln (\mathrm{d} \alpha / \mathrm{dt})$ versus $1 / \mathrm{T}_{\alpha}$ (i.e. the temperature at each fraction point, $\alpha$ ), and fitting the data to a straight line, the values for $\mathrm{E}_{\alpha}$ and $\ln \left\{\mathrm{A}_{\alpha} \mathrm{f}(\alpha)\right\}$ can be calculated. These values are dependent on the extent of the reaction. Typically the first and last $10 \%$ of the reaction are erroneous due to small signal-to-noise ratios of the data.

In the $\mathrm{n}^{\text {th }}$ order Arrhenius analysis $\mathrm{f}(\alpha)$ is replaced with the term $(1-\alpha)^{\mathrm{n}}$ resulting in equation (3):

$$
\frac{d \alpha}{d t}=k f(\alpha)=A e^{-E / R T}(1-\alpha)^{n}
$$

The extended-Prout-Tompkins (e-PT) model is a nucleation and growth, global-kinetic-model $[15,16]$; the e-PT model is shown in equation 4 :

$$
\frac{d \alpha}{d t}=\left(A e^{-E / R T}\right)(1-\alpha)^{n}(1-q(1-\alpha))^{m}
$$

where $\alpha$ is the fraction reacted, $\mathrm{E}$ is the activation energy, $\mathrm{R}$ is the gas constant, $\mathrm{T}$ is temperature, $\mathrm{A}$ is the preexponential factor, and $\mathrm{n}, \mathrm{m}$, and $\mathrm{q}$ are unitless variables associated with the reaction order, autocatalysis and nucleation, respectively. The e-PT model is appropriate for modeling the kinetics of autocatalytic decomposition and 
is used to model many energetic material decompositions [17, 18]. In most cases, the material decomposition involves multiple stages necessitating a parallel reaction model with a weighting factor for each stage. Equation 5 is applicable to both the $\mathrm{n}^{\text {th }}$ order model (Eq. 3) and the e-PT model (Eq. 4):

$$
\frac{d \alpha}{d t}=\sum_{i=1}^{\max } w_{i} k_{i} f_{i}(\alpha)
$$

where $w$ corresponds to the weight factor and subscript $i$ is used for indexing purposes.

The isoconversional analysis was performed using the AKTS Thermokinetics software [19]. Fits and predictions using the $\mathrm{n}^{\text {th }}$ order Arrhenius model and the e-PT model were performed using the program Kinetics05 [20]. In all the model fitting analysis (i.e. $\mathrm{n}^{\text {th }}$ order and e-PT model fitting), the best model and parameters were assessed via the sum of the squares of the weighted normalized residuals.

\section{Results and Discussion}

\subsection{Thermal Decomposition Experiments}

The differential scanning calorimetry (DSC) results of PBXN-9, shown in Figure 1, display an endothermic peak (i.e. endotherm) at $188^{\circ} \mathrm{C}$, a small exothermic peak (i.e. exotherm) between $210-240{ }^{\circ} \mathrm{C}$, and a large exotherm at $280{ }^{\circ} \mathrm{C}$. The endotherm corresponds to the $\beta \rightarrow \delta$ polymorphic transition of HMX and the large exotherm at 280 ${ }^{\circ} \mathrm{C}$ correspond to the decomposition of HMX; slower scan data reveals that this peak is actually comprised of two peaks as will be discussed later in the context of the TGA data. Figure 1 also shows the DSC curve for LX-07, an HMX-Viton formulation. In the LX-07 curve, the endotherm at ca. $200^{\circ} \mathrm{C}$ is assigned to the $\beta \rightarrow \delta$ polymorphic transition of HMX and the large exotherm at $283{ }^{\circ} \mathrm{C}$ is assigned to the HMX decomposition. In comparing the LX07 and PBXN-9, the temperature shift in the polymorphic transition may be due to differences in heat transfer rates or binder properties;[21] however, it may simply result from the variability in the data due to the relatively high heating rate of $10{ }^{\circ} \mathrm{C} / \mathrm{min}$. The inset in Figure 1 displays an enlargement of the three curves in which the small exothermic peak for PBXN-9 is easier to observe; the LX-07 curve shows no exotherm in this region. The small exothermic peak is also absent in the DSC results for LX-04 (an HMX-Viton formulation, not shown) and neat HMX (not shown).

DSC results for the binder (Hytemp) and the binder + plasticizer (Hytemp + DOA) are shown in Figure 2. Three identical experiments on neat Hytemp indicate that the binder does not begin to decompose until $\sim 350{ }^{\circ} \mathrm{C}$. Three identical experiments with Hytemp + DOA show a small exotherm at ca. $240-255^{\circ} \mathrm{C}$. In all of these experiments, the samples were prepared and sealed on the bench-top; hence, despite the hermetic seal the gaseous environment prior to decomposition is not inert. Most likely, both the Hytemp and DOA undergo some oxidative degradation; although it is unknown if the reaction is completely oxidative or if there is some non-oxidative degradation. Based on these results, the small exotherm in the Hytemp +DOA mixture and the small exotherm in the PBXN-9 experiments are both attributed to DOA degradation.

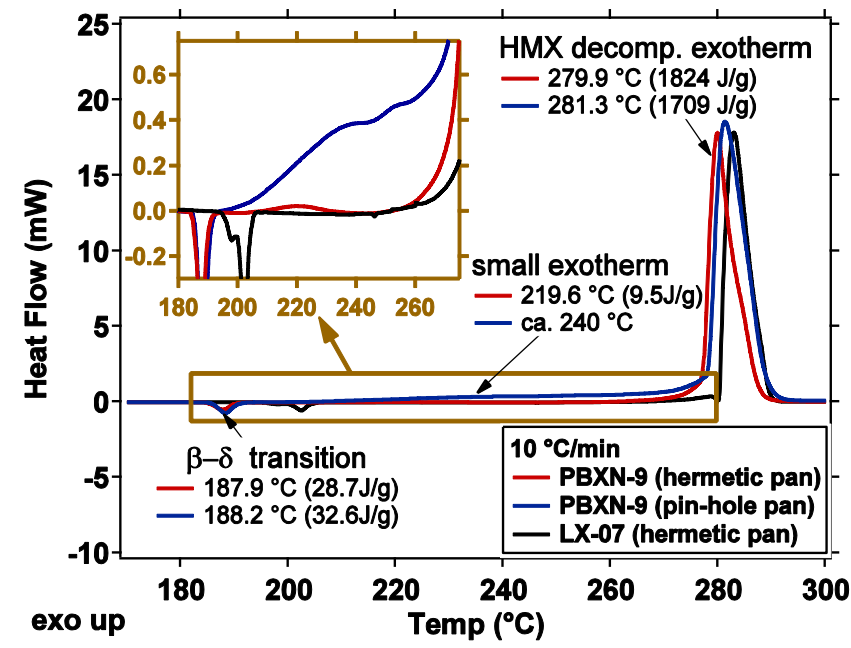

Figure 1. DSC results for PBXN-9 and LX-07 in two different pan types. 


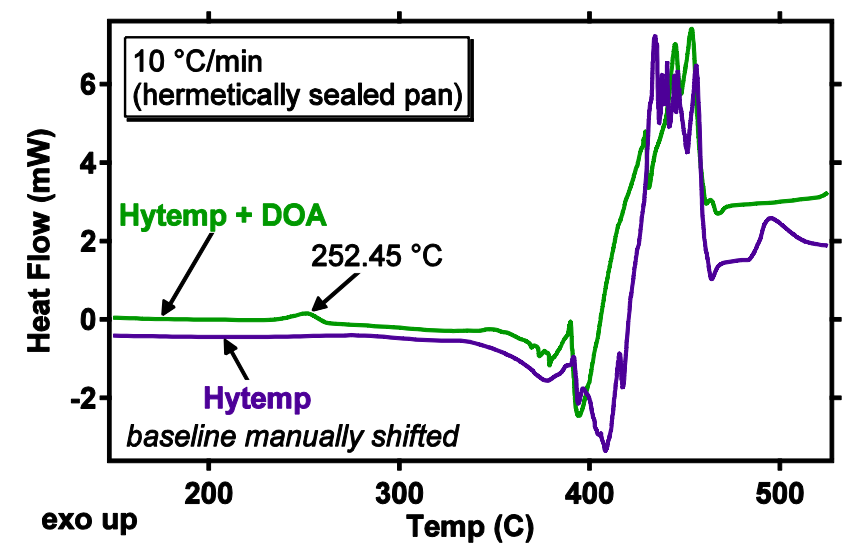

Figure 2. DSC results for Hytemp and Hytemp + DOA

Thermogravimetric analysis (TGA) results of PBXN-9 and its constituents are shown in Figure 3. PBXN-9 displays two-step weight loss with $\sim 6 \%$ loss between 150 and $230{ }^{\circ} \mathrm{C}$ and the remaining between 230 and $290{ }^{\circ} \mathrm{C}$. Slow heating rate data for PBXN-9 demonstrate that this major weight loss step produces two exothermic peaks, as shown in Figure 5. The TGA results for neat-Hytemp indicate a two-step weight loss that begins at $\sim 300{ }^{\circ} \mathrm{C}$. Heat flow measurements, however, indicate that the degradation of Hytemp involves at least three prominent stages (see Appendix Figure A1). Neat DOA has a single weight-loss step between 170 and $280{ }^{\circ} \mathrm{C}$. The Hytemp + DOA mixture displays a three-step weight loss that begins at $\sim 170{ }^{\circ} \mathrm{C}$. Based on the onset temperatures and the weight loss percentages, the most logical conclusion is that the DOA either evaporates and/or degrades (oxidatively or nonoxidatively) resulting in the $\sim 6 \%$ weight loss in PBXN-9 and the $\sim 75 \%$ weight loss in the Hytemp + DOA mixture.

The role of the gaseous environment was studied briefly in these material degradations. Figure 4 shows the results of simultaneous TGA and DTA (differential thermal analysis) of Hytemp + DOA in both an air and a nitrogen environment; Figure 5 shows the results of PBXN-9 degradation in air and nitrogen. Hytemp and DOA react exothermically in air and endothermically in nitrogen; these results are not surprising since the oxygen in the air can produce oxidative degradation of the materials. In the case of PBXN-9, there are more subtle changes in both the weight loss and heat flow. The results indicate that the final stage of decomposition, which is assigned to HMX decomposition, is slightly retarded in an air environment in comparison with nitrogen. These results are interesting because HMX already contains oxygen; hence the change in gaseous environment was not expected to impact the material decomposition. Further studies are necessary to understand the reason for this phenomenon; however, these results clearly demonstrate the importance of the gaseous environment in utilizing kinetic parameters and results from this study. All kinetic analyses of these materials were performed using data collected in ultra-zero air. The nitrogen gas experiments will not be discussed henceforth in the main text, however, the appendix includes a kinetic analysis of PBXN-9 in an $\mathrm{N}_{2}$ atmosphere (Appendix Figures A3 and A4 and Tables A1 and A2).

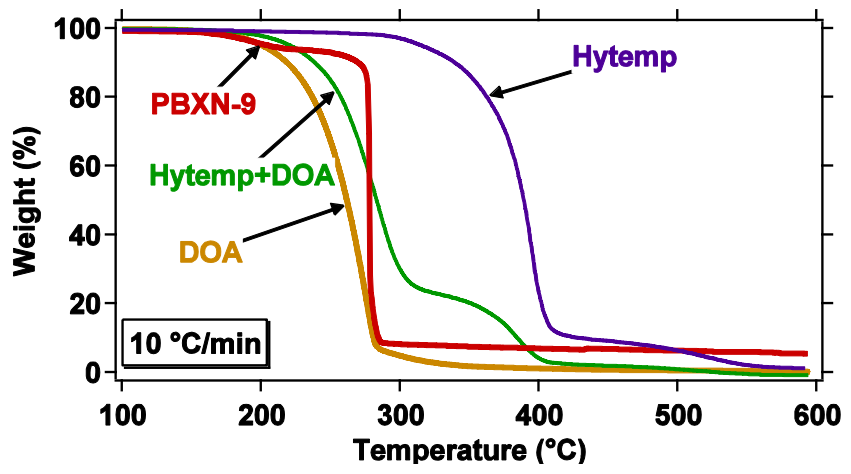

Figure 3. TGA results for PBXN-9, Hytemp, DOA, and Hytemp + DOA 


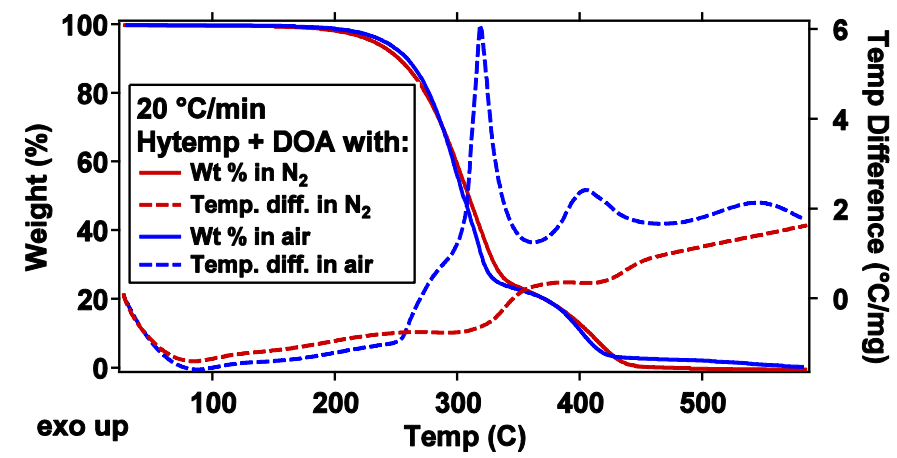

Figure 4. TGA and DTA results for Hytemp + DOA in air and $\mathrm{N}_{2}$ atmosphere.

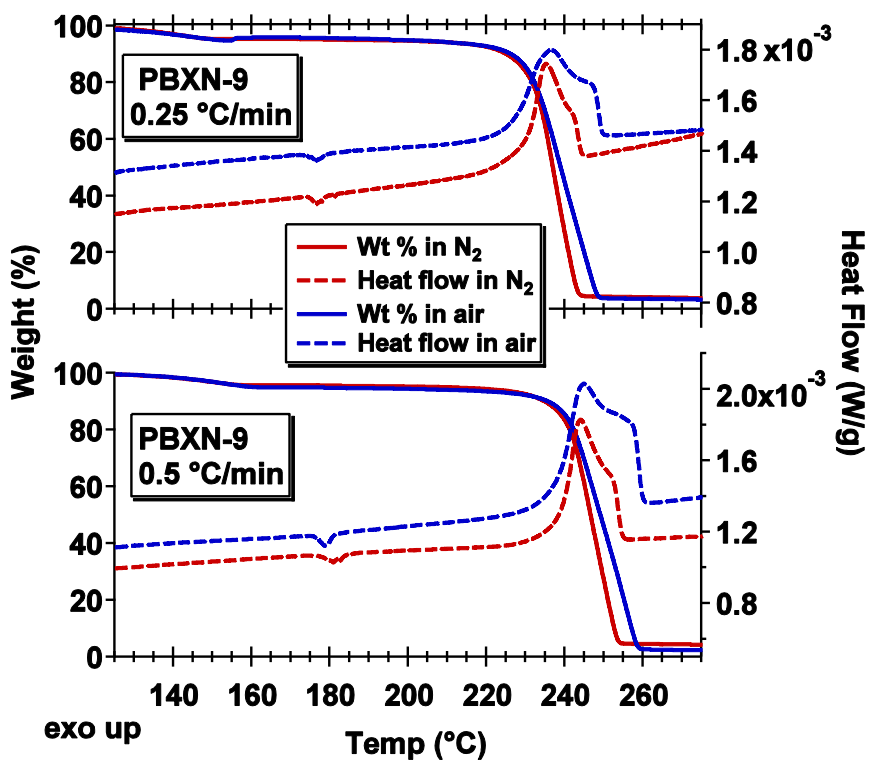

Figure 5. Weight loss and heat flow results for PBXN-9 in air and $\mathrm{N}_{2}$ atmosphere.

\subsection{Thermal Decomposition Kinetics}

\subsubsection{Hytemp and DOA kinetics}

The kinetics of the binder and plasticizer decomposition were determined by fitting the TGA curves to different kinetic models. All attempts to fit the DOA and Hytemp data to the extended Prout-Tompkins (e-PT) returned a negative value for ' $\mathrm{m}$ ', which is not logical for these decomposition reactions. The ' $\mathrm{m}$ ' value in the e-PT model is generally correlated with the degree of autocatalysis; a larger number indicates that during the decomposition, the population of reactive decomposition intermediates increases and accelerates further decomposition. Logically, a negative ' $\mathrm{m}$ ' would imply the opposite of autocatalysis (i.e. reactive intermediates suppressing further reactions) which is not a common phenomenon in chemical reactions unless a chemical equilibrium is established. Instead an $\mathrm{n}^{\text {th }}$ order Arrhenius model was used for all the DOA and Hytemp degradation kinetics because it is a relatively simple model-based analysis method that has been used frequently in the decomposition kinetics of organic polymers $[22,23]$.

The decomposition of Hytemp appears to involve two-stages according to Figure 3, however, inspection of the heat flow of Hytemp clearly indicates that there are three reaction stages (see Appendix Figure A1). In the 10 ${ }^{\circ} \mathrm{C} /$ min TGA experiments, the first stage occurs between ca. 280 and $340{ }^{\circ} \mathrm{C}$, the second stage begins at ca. $340{ }^{\circ} \mathrm{C}$, and the final stage begins at ca. $420^{\circ} \mathrm{C}$. Results of the $\mathrm{n}^{\text {th }}$ order fit of Hytemp to a three-stage model are listed in Table 2; predictions using the $\mathrm{n}^{\text {th }}$ order kinetic parameters show a good match with raw data, see Figure 7(b). 
The isoconversional analysis of the Hytemp data is shown in Figure 6(a). In the first $10 \%$ of the reaction, the isoconversional analysis indicates that the activation energy rises from $100 \mathrm{~kJ} / \mathrm{mol}$ up to $175 \mathrm{~kJ} / \mathrm{mol}$; this starting energy matches the first-stage $\mathrm{n}^{\text {th }}$ order analysis result of $100 \mathrm{~kJ} / \mathrm{mol}$. Between 10 and $80 \%$ (i.e. $\alpha=0.1-0.8$ ) the activation energy appears to be fairly consistent; the average value is $184 \mathrm{~kJ} / \mathrm{mol}$ (see Table 3). This barrier is similar to the latter two barriers determined using the $\mathrm{n}^{\text {th }}$ order fit (i.e. 198 and $183 \mathrm{~kJ} / \mathrm{mol}$, see Table 2). Typically the first and last $10 \%$ of the reaction can be erroneous due to a small signal-to-noise ratios of the data. However, in the isoconversional analysis of Hytemp, the activation energies in the last $20 \%$ appear to span an unreasonably wide range of values. Inspection of the raw data and isoconversional predictions of the reaction progress, see Figure 7(a), indicate that the isoconversional method does a very poor job fitting the final stage of decomposition; thus these values above ca. $80 \%$ are not valid. Although it is difficult to see in Figure 7, above 86\% the decomposition curves at different heating rates cross over each other (see Figure A2 in Appendix for a close-up of this region), indicating a change of mechanism as the heating rate changes, which explains the poor isoconversional fits above $80 \%$. Previous work has demonstrated that slower heating rates in polymer decomposition promotes coke formation [24] and results in curve crossing at different heating rates; it seems plausible that a similar process is occurring in Hytemp resulting in the curve crossing observed in the final stage of the reaction.

Based on the thermal analysis experiments and kinetic analysis, DOA appears to evaporate and/or decompose in a single stage with a relatively small activation energy. Table 2 lists the DOA decomposition kinetics using the $\mathrm{n}^{\text {th }}$ order model. The isoconversional analysis of the DOA decomposition data is shown in Figure 6(b). The average activation energy between 10 and $90 \%$ is $84 \mathrm{~kJ} / \mathrm{mol}$ (see Table 3), which is remarkably consistent with the $86 \mathrm{~kJ} / \mathrm{mol}$ activation energy calculated in the $\mathrm{n}^{\text {th }}$ order analysis. Comparison of $\mathrm{n}^{\text {th }}$ order predictions with raw data show excellent agreement, as do the predictions using the isoconversional analysis, see Figure 8. The kinetics of DOA evaporation from poly(vinly chloride) (i.e. PVC) was studied previously and the activation energies and Arrhenius pre-exponential factors are similar to our measurements for neat-DOA and our more complex mixtures of Hytemp+DOA and PBXN-9 [25].

The mixture of Hytemp + DOA was analyzed using TGA and the isoconversional results are shown in Figure 6(c) and a comparison of the raw data to the isoconversional predictions is shown in Figure 9(a). There is a precipitous drop in activation energy with a local minimum at $\alpha=75$; the mixture was prepared with 73.6\% DOA, hence this drop most likely represents the demarcation between DOA and Hytemp reactions. In the region below $\alpha$ $=75$, the activation energy appears flat with a value of $75 \mathrm{~kJ} / \mathrm{mol}$ for most of the reaction (see Table 3); there are, however, two small excursions to ca. $95 \mathrm{~kJ} / \mathrm{mol}$ at $\alpha=10$ and $\alpha=60$. Similarly, the isoconversional analysis of neat-DOA in Figure 6(b) shows a spike in the activation energy in the last $5 \%$ of the reaction; this sudden rise in activation energy could be due to more complex reactions in the final stages of DOA degradation. The mixture's activation energy above $\alpha=75$ is attributed to mostly Hytemp chemistry; it is rather variable, however, this is not surprising as there is only a small amount of Hytemp in the sample and the chemistry is most likely complicated by any nonvolatile residue left after the DOA decomposes.

A fit of the Hytemp + DOA to the $\mathrm{n}^{\text {th }}$ order model was performed using a three-stage model and the results are listed in Table 2; comparisons of the raw data with $\mathrm{n}^{\text {th }}$ order predictions are shown in Figure 9. A four-stage model would have been more rigorous, since Hytemp alone has three stages of decomposition; however, the software Kinetics- 05 only allows for three-parallel reactions and above three reactions, the number of fitting variables becomes excessive. In our three-stage $\mathrm{n}^{\text {th }}$ order fit, the first stage of decomposition has an activation energy of 84 $\mathrm{kJ} / \mathrm{mol}$ and a weight factor of 74 ; the weight factor is consistent with the $74 \%$ DOA in the mixture and the activation energy is nearly identical to the activation energy for neat-DOA. The remaining reactions in the $\mathrm{n}^{\text {th }}$ order fit to the mixture are assigned to Hytemp; the kinetic parameters are not unreasonable but they do differ from the neatHytemp values. The most likely explanation is that the reactions are more complex in the presence of any residual material left after the DOA reactions are complete. In general, the evaporation/degradation kinetics of the DOA in the mixture are similar to the neat-DOA kinetics, indicating that the DOA reactions are relatively unaffected by the presence of Hytemp.

\subsubsection{PBXN-9 kinetics}

The decomposition of PBXN-9 appears to have three distinct stages; the first occurs at ca. $150{ }^{\circ} \mathrm{C}$ degrees and is assigned to DOA evaporation and/or degradation. The second and third stages are distinguishable when looking at the heat flow (the two steps are indistinguishable in the weight loss curve in Figure 3; see Figure 5 for the heat flow of PBXN-9). These two stages most likely entail two stages of HMX decomposition as doublet peaks have been observed previously in our DSC measurements of neat HMX (not shown). The Hytemp decomposition is either indistinguishable in these experiments (due to its small weight percent in the formulation it may be difficult to observe in the experiments) or is part of the HMX decomposition (caustic transient species produced via the 
complex mechanisms of HMX may be able to attack the organic binder). The kinetics of PBXN-9 were analyzed using the isoconversional analysis method and one can see three distinct regions in Figure 6(d); Figure 10(a) shows the comparisons of the raw data to the isoconversional predictions.

The kinetics of PBXN-9 decomposition were modeled using the extended-Prout-Tomkins model, which is appropriate for the autocatalytic decomposition reactions of HMX [17, 18]; see Table 2 for the optimized kinetic parameters. These parameters were found by inputting estimated values based on the isoconversional analysis and then allowing the program Kinetics 05 to search for the combination of values that best fits the data. Figure 10 shows comparisons of the e-PT predictions to raw data. One should note that the first stage of decomposition, i.e. the stage that is mainly attributed to DOA evaporation/degradation was fit using a fixed value of $\mathrm{m}=0$ which reduces the ePT model to the simpler $\mathrm{n}^{\text {th }}$ order model, hence, these e-PT fits are actually a combination of $\mathrm{n}^{\text {th }}$ order for the first stage and e-PT for the latter stages.

In the three-stage e-PT fit to the PBXN9 data, the barriers are generally consistent with the results from the constituent materials and the PBXN-9 isoconversional analysis. The first stage of decomposition (i.e. the first $4-6$ $\%$ ) has a barrier of $96 \mathrm{~kJ} / \mathrm{mol}$, this stage has already been assigned to the evaporation/degradation of DOA, which was $86 \mathrm{~kJ} / \mathrm{mol}$ when tested alone. The second and third stages are attributed to mostly HMX decomposition, the barriers range from $141-195 \mathrm{~kJ} / \mathrm{mol}$. Previously Brill et al. compiled the kinetic parameters from a variety of different thermal analysis studies of HMX decomposition and reported activation energies that ranged from 54 to $280 \mathrm{~kJ} / \mathrm{mol}$ [17]. Brill reported that the activation energy varied due to the kinetic compensation effect of the Arrhenius pre-exponential factor (i.e. A) [17]; although, it is not unreasonable that some of the variability may also be due to competing reaction mechanisms that are promoted or suppressed under different experimental conditions. Plotted in Figure 11 are the kinetic parameters A vs. $\mathrm{E}_{\mathrm{a}}$ complied by Brill on neat HMX and calculated here for PBXN-9. In comparison with the $\mathrm{A} / \mathrm{E}_{\mathrm{a}}$ pairs in Brill et al's analysis, our $\mathrm{A} / \mathrm{E}_{\mathrm{a}}$ pairs are a bit low and do not fall on the standard A vs. $E_{a}$ line. A recent study of HMX decomposition at various pressures indicates that even under very different pressures and temperatures, the $\mathrm{A} / \mathrm{E}_{\mathrm{a}}$ pairs still fall on the standard line [3]. The offset observed in Figure 11 is most likely a result of the Hytemp binder and any DOA residue present in PBXN-9; Brill's analysis was of HMX decomposition without binder.

Table 2. Kinetic parameters for PBXN-9 and its constituent from TGA. All the e-PT fits used the value of q=0.999.

\begin{tabular}{|l|c|c|c|c|c|c|}
\hline Sample & $\begin{array}{c}\mathbf{A} \\
\mathbf{( 1 / s )}\end{array}$ & $\begin{array}{c}\mathbf{E} \\
\mathbf{( k J / m o l})\end{array}$ & $\mathbf{n}$ & $\mathbf{m}$ & $\begin{array}{c}\text { Weight } \\
\text { factor }\end{array}$ & $\begin{array}{c}\text { Kinetic } \\
\text { Model }\end{array}$ \\
\hline Hytemp 4454 & $3.05 \mathrm{E}+06$ & 100 & 0.97 & na & 0.11 & $\mathrm{n}^{\text {th }}$ order \\
& $3.17 \mathrm{E}+13$ & 198 & 0.76 & na & 0.78 & \\
& $1.22 \mathrm{E}+10$ & 183 & 1.75 & na & 0.11 & \\
\hline DOA & $9.92 \mathrm{E}+05$ & 86 & 0.39 & na & 1.0 & $\mathrm{n}^{\text {th }}$ order \\
\hline DOA+Hytemp & $4.29 \mathrm{E}+05$ & 84 & 0.39 & na & 0.74 & $\mathrm{n}^{\text {th }}$ order \\
& $6.62 \mathrm{E}+07$ & 126 & 0.69 & na & 0.23 & \\
& $4.12 \mathrm{E}+12$ & 218 & 2.07 & na & 0.03 & \\
\hline PBXN-9 & $3.48 \mathrm{E}+08$ & 96 & 0.80 & 0 & \\
& $2.18 \mathrm{E}+11$ & 141 & 0.13 & 0.68 & $0.30^{\text {(fixed) }}$ & e-PT \\
& $1.00 \mathrm{E}+17$ & 195 & 1.16 & 0.87 & $0.65^{\text {(fixed) }}$ & \\
\hline
\end{tabular}




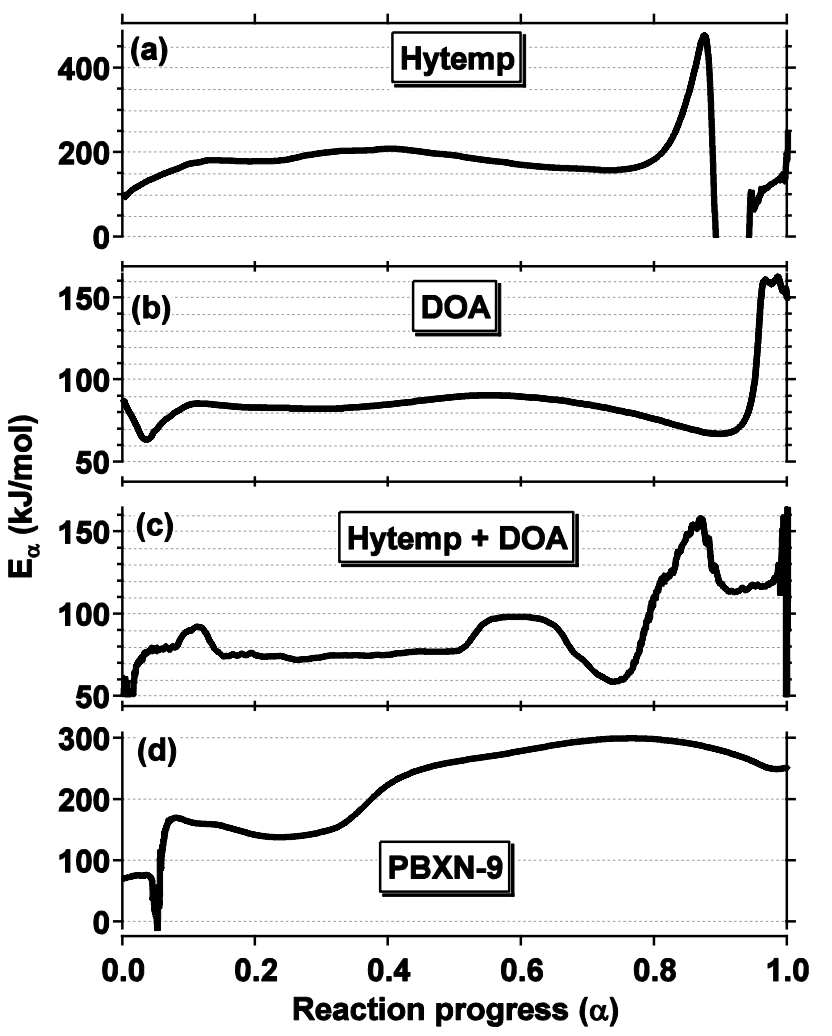

Figure 6. Decomposition kinetics from the isoconversional analysis of TGA data for (a) Hytemp 4454 (b) DOA (c) Hytemp + DOA and (d) PBXN-9.

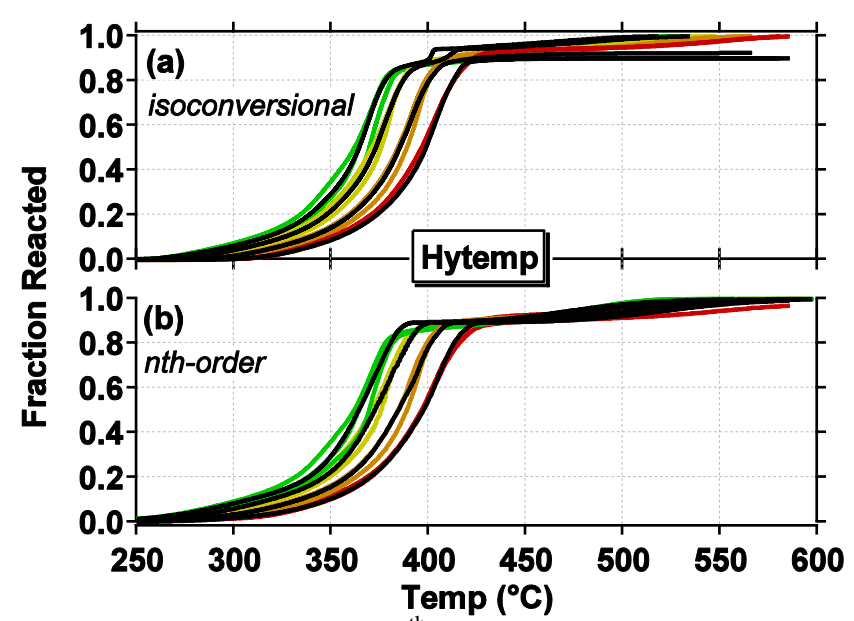

Figure 7. Comparison of (a) isoconversional and (b) $\mathrm{n}^{\text {th }}$-order predictions with raw data for the decomposition of Hytemp; colored lines are raw data, black lines are fit-predictions. 


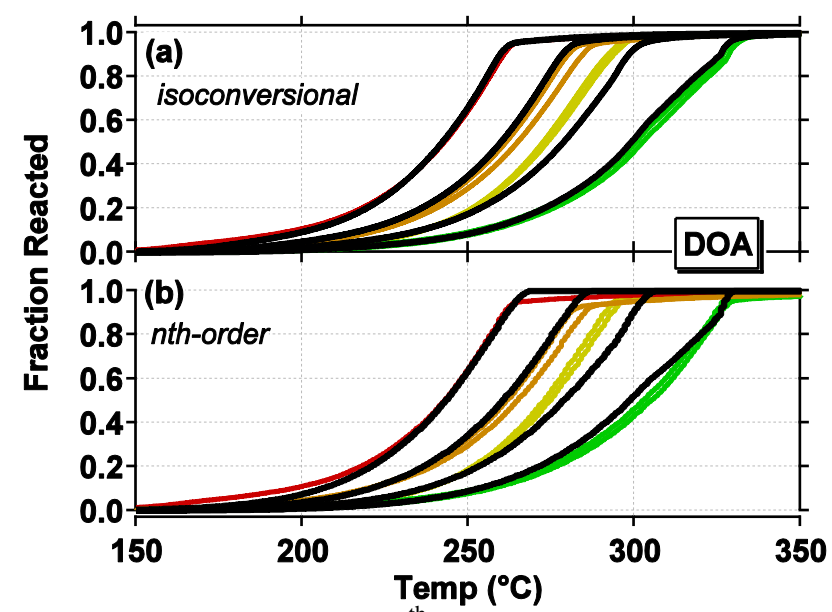

Figure 8. Comparison of (a) isoconversional and (b) $\mathrm{n}^{\text {th }}$-order predictions with raw data for the decomposition of DOA; colored lines are raw data, black lines are fit-predictions.

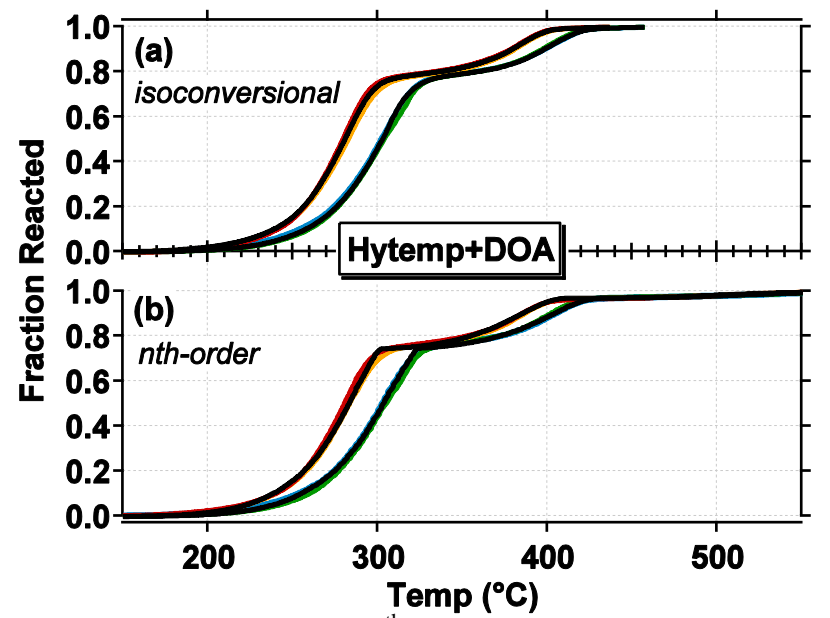

Figure 9. Comparison of (a) isoconversional and (b) $\mathrm{n}^{\text {th }}$-order predictions with raw data for the decomposition of the mixture Hytemp + DOA; colored lines are raw data, black lines are fit-predictions.

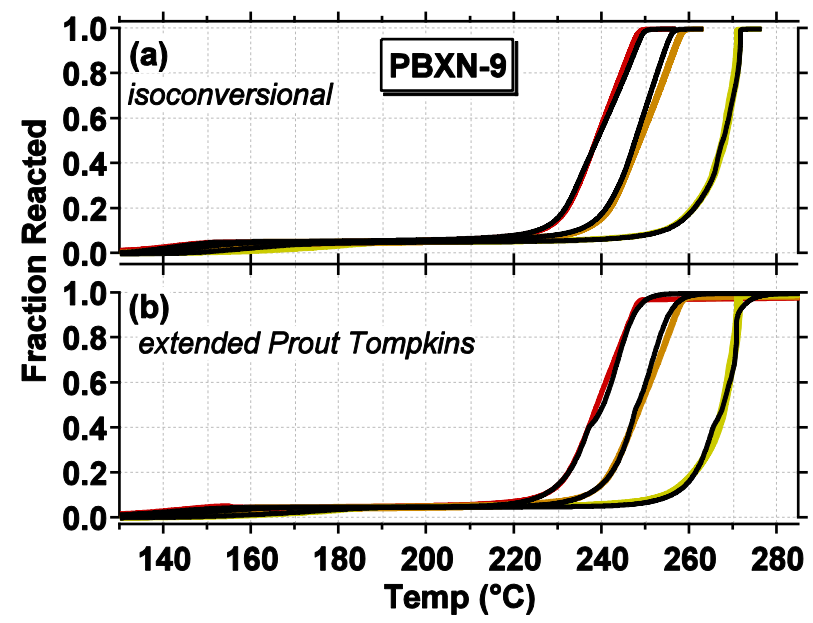

Figure 10. Comparison of (a) isoconversional and (b) extended-Prout-Tompkins (3-stage model) predictions with raw data for the decomposition of the PBXN-9; colored lines are raw data, black lines are fit-predictions. 
Table 3. Average values from isoconversional analysis of PBXN-9 and its constituents from TGA. Complete results are shown in Figure 6.

\begin{tabular}{|l|l|l|}
\hline Sample & $\mathbf{E} \mathbf{( k J / m o l})$ & Range of averaging \\
\hline Hytemp 4454 & 184 & $0.1-0.8$ \\
\hline DOA & 84 & $0.1-0.9$ \\
\hline Hytemp + DOA & 75 & $0.15-0.5$ \\
\hline PBXN-9 & 75 & $0.0-0.04$ \\
& 144 & $0.1-0.3$ \\
& 283 & $0.5-1.0$ \\
\hline
\end{tabular}

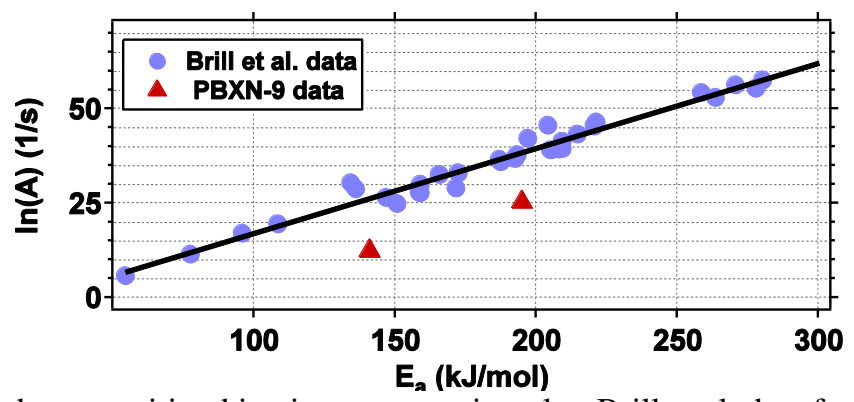

Figure 11. HMX thermal decomposition kinetic compensation plot. Brill et al. data from Table 1 in reference [17].

In summary, our thermal decomposition analysis demonstrates that upon heating PBXN-9, the plasticizer (i.e. DOA) will react and/or evaporate prior to HMX decomposition. Consequently, the thermal damage induced in PBXN-9 upon heating above $160{ }^{\circ} \mathrm{C}$ may result from both the increase in porosity due to the $\beta \rightarrow \delta$ polymorphic transition and the loss of material due to the evaporation/degradation of DOA. One important difference between these thermal analysis experiments and thermal damage experiments, which will be discussed in the following section, is the sample shape. In this thermal analysis, we used PBXN-9 prill/beads rather than pressed parts. The surface to volume ratio is expected to affect the extent of decomposition/evaporation of DOA, consequently a large pressed part may experience less DOA loss, especially in the interior.

\subsection{Thermally induced damage}

In general, the thermally damaged PBXN-9 pressed part samples expanded, lost weight, changed color, and formed cracks, resulting in lower density, greater porosity and gas permeability. All these changes are attributed to the thermal exposure. Optical and scanning electron microscope (SEM) images of the samples before and after thermal exposure are shown in Figures 12 and 13, respectively. Both post-exposure images show formation of cracks which are 10's to 100's of micrometers long. Pre- and post-exposure measurements of the sample weight, volume, and porosity were performed according to published procedures [7] and are reported in Table 4. Methods for calculating the fraction of open and closed pores are described in the literature [26].

Previous measurements of HMX-Viton formulations show no significant weight loss after exposure to similar heating conditions. According to our decomposition kinetics, HMX should be relatively stable at $180{ }^{\circ} \mathrm{C}$, however, the plasticizer, DOA, is quite volatile hence the sample weight loss in the thermally damaged PBXN-9 is attributed to mostly evaporation/degradation of the plasticizer. A thermogravimetric experiment on the binder+plasticizer (i.e. Hytemp + DOA) was performed using a heating profile similar to the thermal-damage experiments (i.e. 3 hrs at 180 ${ }^{\circ} \mathrm{C}$ ). The results are shown in Figure 14; nearly 50\% weight loss of the sample is observed and is attributed to decomposition/evaporation of DOA.

Using the kinetic data provided in Table 2 (e-PT three stage model) and a temperature profile of 3 hours at 180 ${ }^{\circ} \mathrm{C}$, we predict that there should be ca. $5 \%$ weight loss. The results presented in Table 4 , however, only indicate $2.6 \%$ weight loss. Table 4 reports the changes in pressed parts whereas molding powder (i.e. prill) was used for determining the kinetics presented in Table 2. Most likely, the plasticizer gets trapped in the pressed parts and the weight loss is restricted in comparison with a powder/prill sample. 
The increase in volume and corresponding decrease in bulk density are mainly attributed to the $\beta \rightarrow \delta$ transition introduces irreversible damage to the pressed parts. Previous measurements of HMX-Viton formulations show similar, but less dramatic, response to elevated temperatures; for example, the density of LX-04 decreased by $7 \%$ and LX-10 decreased by $12.5 \%$, whereas PBXN-9 bulk density decreased by $13.5 \%$ [7]. These density changes correlate well with the weight percent of HMX: LX-04 contains 85\% HMX, LX-10 has 94.5\%, and PBXN-9 contains $92.8 \%$. The large increase in porosity and decrease in bulk density in PBXN-9 reported in Table 2 is attributed to both the damage induced by the $\beta \rightarrow \delta$ polymorph transition and the loss of material due to evaporation/degradation of DOA.

Gas permeability measurements of pristine PBXN-9 samples of various densities were performed in order to quantitatively correlate gas permeability with sample density; these values are reported in Table 5. Due to concern about the structural integrity of a pristine part pressed to a density less than ca. $89 \%$ TMD, lower density samples were not prepared or measured. As expected, the gas permeability increases as the part density decreases. When a 97.7\% TMD part was thermally damaged $\left(180^{\circ} \mathrm{C}\right.$ for $\left.3 \mathrm{hrs}\right)$, cooled to room temperature and analyzed in the permeameter, the gas permeability was considerably lower than the lowest density pristine part (see Table 5). The density of this thermally damaged part was therefore estimated to be less than 89.3\% TMD.

The gas permeability of a hot-PBXN-9 part was measured in-situ at two different temperatures. In this experiment, a pristine part was potted to the holder, measured at ambient temperature, heated to a pre-determined temperature at a specified ramp rate, thermally soaked, and measured. Figure 15 shows the results of the in-situ measurements made on PBXN-9. By this approach, it is possible to estimate material density (real-time) during heating by using the density-permeability correlation in Table 5 . The increase in permeability and decrease in density at $150{ }^{\circ} \mathrm{C}$ is attributed to evaporation of the DOA plasticizer as well as some thermal expansion of the part. The large increase in permeability at $180^{\circ} \mathrm{C}$ is attributed to the combined effects of DOA loss, thermal expansion, and the porosity introduced due to the $\beta-\delta$ transition. Previous measurements on LX-04, LX-07, and LX-10 show similar gas permeability changes after thermal damage, however PBXN-9 experiences the most dramatic increase in permeability [7]. These results are consistent with the porosity and density results discussed above.
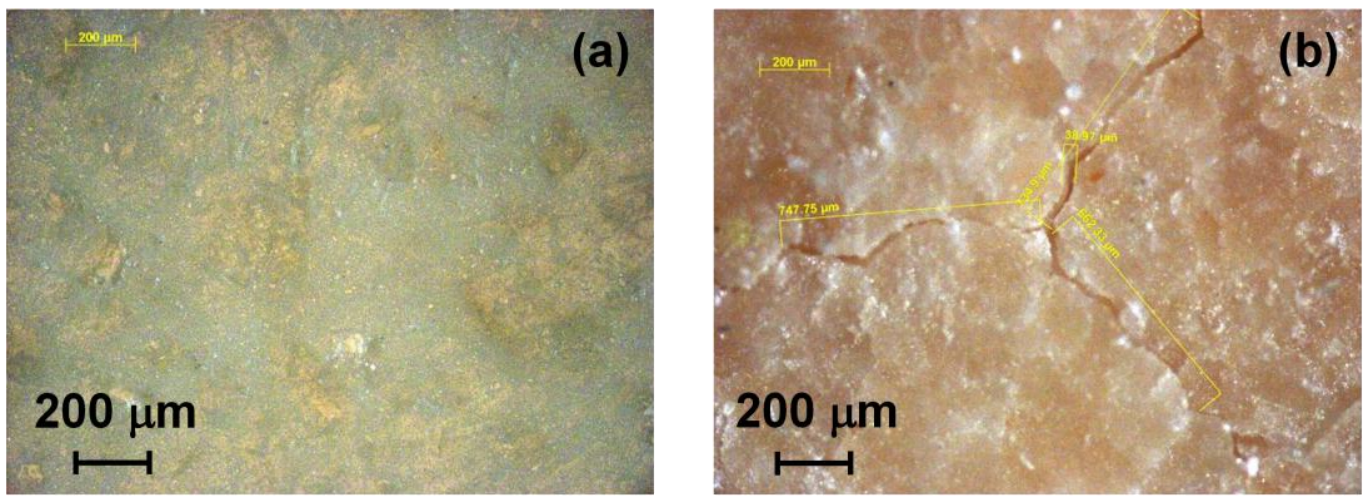

Figure 12. Microscopic pictures of pressed part, (a) before and (b) after heating for 3 hours at $180{ }^{\circ} \mathrm{C}$.
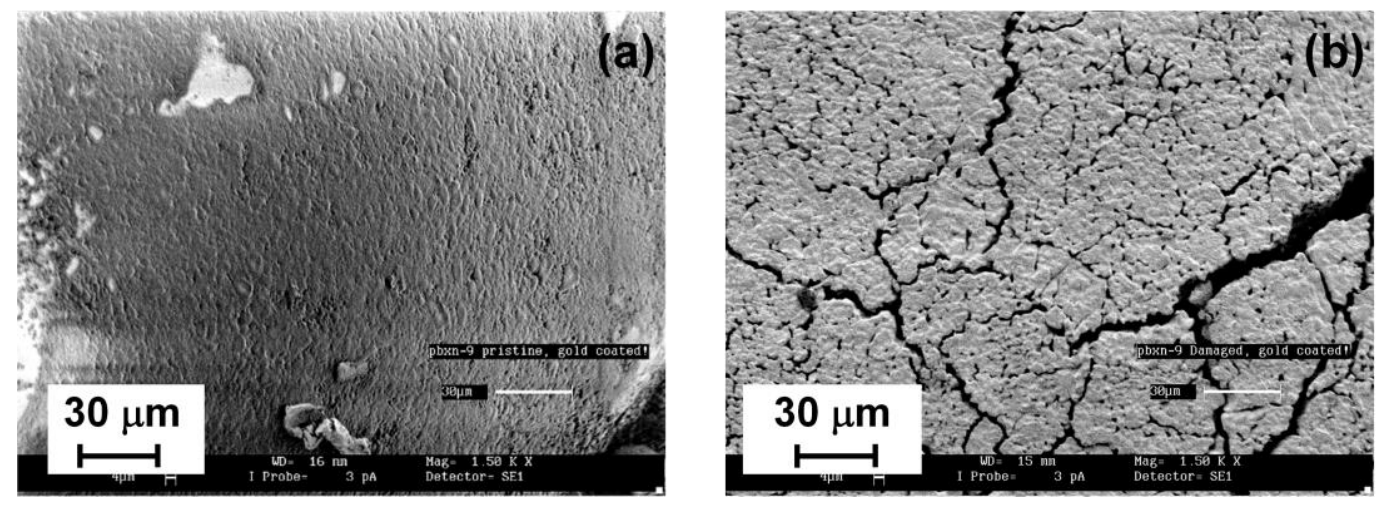
Figure 13. SEM pictures of PBXN-9 prill, (a) before and (b) after heating for 3 hours at $180{ }^{\circ} \mathrm{C}$. The magnification was 1500 .

Table 4. PBXN-9 sample weight, bulk volume, and porosity before and after heating for 3 hours at $180{ }^{\circ} \mathrm{C}$.

\begin{tabular}{|c|c|c|c|c|c|}
\hline Sample & $\begin{array}{c}\text { Weight } \\
(\mathrm{g})\end{array}$ & $\begin{array}{c}\text { Bulk } \\
\text { volume } \\
(\mathrm{cc})\end{array}$ & $\begin{array}{c}\text { Total } \\
\text { porosity } \\
(\%)\end{array}$ & $\begin{array}{c}\text { Fraction of } \\
\text { closed } \\
\text { pores }\end{array}$ & $\begin{array}{c}\text { Fraction of } \\
\text { open pores }\end{array}$ \\
\hline Pristine & 1.8989 & 1.090 & $2.4 \%$ & $0.4 \%$ & $2.0 \%$ \\
\hline Damaged & 1.8486 & 1.227 & $15.5 \%$ & $1.6 \%$ & $13.9 \%$ \\
\hline \% Change & $\begin{array}{c}-0.05 \\
(-2.6 \%)\end{array}$ & $\begin{array}{c}0.137 \\
(12.6 \%)\end{array}$ & $+13.1 \%$ & $+1.2 \%$ & $+11.9 \%$ \\
\hline
\end{tabular}

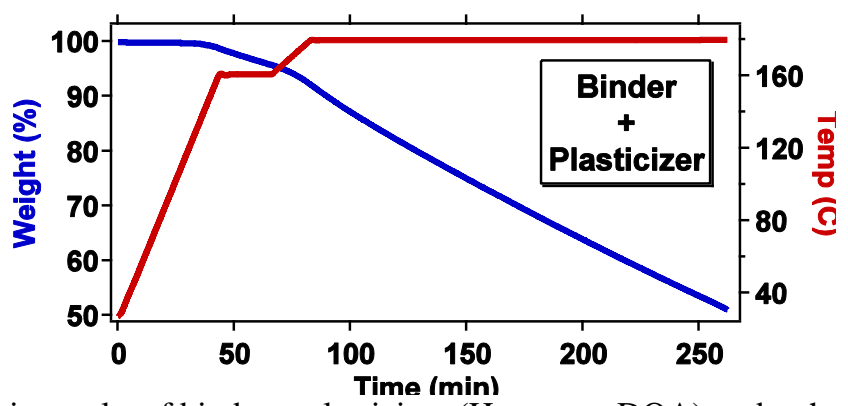

Figure 14. Thermogravimetric results of binder + plasticizer (Hytemp + DOA) under thermal conditions similar to those used in the thermal damage experiments (i.e. $3 \mathrm{hrs}$ at $180^{\circ} \mathrm{C}$ ).

Table 5. Gas permeability in PBXN-9 measured at room temperature

\begin{tabular}{|c|c|c|c|c|}
\hline $\begin{array}{c}\text { Sample } \\
\text { description }\end{array}$ & $\begin{array}{c}\text { Temperature of } \\
\text { measurement }\left({ }^{\circ} \mathbf{C}\right)\end{array}$ & $\begin{array}{c}\text { Density } \\
\text { (in \% } \\
\text { TMD) }\end{array}$ & $\begin{array}{c}\text { Gas } \\
\text { permeability } \\
\left(\mathbf{m}^{2}\right)\end{array}$ & Comments \\
\hline Pristine & 22 & $97.7 \%$ & $<10^{-20}$ & Below the detection limit \\
\hline Pristine & 22 & $95.3 \%$ & $1.7 \times 10^{-16}$ & \\
\hline Pristine & 22 & $92.0 \%$ & $3.7 \times 10^{-15}$ & \\
\hline Pristine & 22 & $89.3 \%$ & $2.6 \times 10^{-14}$ & \\
\hline $\begin{array}{c}\text { Damaged } \\
\text { PBXN-9* }\end{array}$ & 22 & $\begin{array}{c}<89.3 \% \\
(\text { estimated) }\end{array}$ & $6.5 \times 10^{-13}$ & $\begin{array}{c}\text { Sample heated for 3 hrs at } 180^{\circ} \mathrm{C} \\
\text { and measured at room temperature }\end{array}$ \\
\hline Hot PBXN-9 & 150 & $\begin{array}{c}93.8 \% \\
(\text { estimated) }\end{array}$ & $8.3 \times 10^{-16}$ & $\begin{array}{c}\text { See Figure 15 for thermal exposure } \\
\text { history }\end{array}$ \\
\hline Hot PBXN-9 & 180 & $\begin{array}{c}89.4 \% \\
\text { (estimated) }\end{array}$ & $2.1 \times 10^{-14}$ & $\begin{array}{c}\text { See Figure 15 for thermal exposure } \\
\text { history }\end{array}$ \\
\hline
\end{tabular}

* The damaged sample was from a 97.7\% TMD pristine part. 


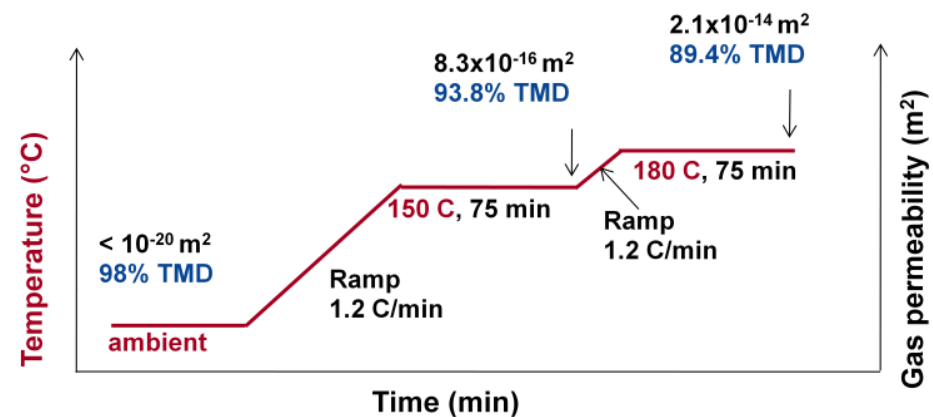

Figure 15. Gas permeability and bulk density at various temperatures for the radially confined PBXN-9 specimen. Densities are calculated based on results of low-density pristine samples reported in Table 5.

\section{Conclusion}

Based on this work, PBXN-9 appears to be more sensitive to elevated temperatures relative to similar HMXformulations. Our thermal decomposition studies clearly show the evaporation/decomposition of the plasticizer (i.e. DOA) prior to HMX decomposition. The volatility of the plasticizer results in significant changes in pressed part morphology and structure even after mild heating. The binder and plasticizer, however, do not affect the kinetics of HMX decomposition significantly and our PBXN-9 decomposition kinetics are similar to those measured and published previously [17]. When parts were heated above the HMX $\beta-\delta$ polymorphic transition temperature, which is approximately $160^{\circ} \mathrm{C}$, samples experienced significant changes in morphology. Most notably, large cracks formed and the sample lost weight and increased significantly in porosity. These changes were observed previously in other HMX-formulations [7] but thermal damage of PBXN-9 produces more porosity and results in higher weight loss than other materials studied.

Results of this work serve as the foundation for understanding and modeling the results of more complex experiments that involve heating. In particular, these results are important in interpreting thermal explosion experiments. The cracks, voids, and the increase in porosity observed in this work could occur prior to a thermal explosion, which would result in faster material deflagration due to the increase in surface area available to the flame. The evaporation of DOA prior to HMX decomposition could create significant pressure changes in a sealed vessel causing vessel fatigue and failure earlier in the thermal explosion. Future studies will look at these more complex studies of PBXN-9 deflagration rates and PBXN-9 thermal explosion.

\section{Acknowledgements}

We gratefully acknowledge Franco Gagliardi and Sally Weber for sample pressing, Gary Hust for material safety testing, and Jon Maienschein for helpful discussion. The Joint DoD-DOE Munitions Technology Development Program is acknowledged for funding. This work performed under the auspices of the U.S. Department of Energy by Lawrence Livermore National Laboratory, 7000 East Avenue, Livermore, CA 94550; under Contract DE-AC52-07NA27344.

\section{Appendix A. Supplementary data}

Supplementary data associated with this article can be found, in the online version, and includes the kinetic analysis of PBXN-9 in a nitrogen gas environment.

\section{References}

[1] J.L. Maienschein, M.R. DeHaven, G.B. Sykora, C.K. Black, J.F. Wardell, M.A. McClelland, O.T. Strand, T.L. Witworth, C. Martinez, Thermal explosion violence for several explosives - measurements and interpretations, in: 13th International Detonation Symposium, Office of Naval Research, Norfolk, VA, 2006, pp. 536.

[2] C.M. Tarver, J.G. Koerner, Effects of endothermic binders on times to explosion of HMX-and TATB-based plastic bonded explosives, J. Energetic Materials, 26 (2008) 1. 
[3] E.A. Glascoe, J.M. Zaug, A.K. Burnham, Pressure dependent decomposition kinetics of the energetic material HMX up to 3.6 GPa, J. Phys. Chem. A, 113 (2009) 13548.

[4] R. Behrens Jr., Thermal Decomposition Processes of Energetic Materials in the Condensed Phase at Low and Moderate Temperatures, in: R.W. Shaw, T.B. Brill, D.L. Thompson (Eds.) Overviews of Recent Research on Energetic Materials, World Scientific Publishing Co. Pte. Ltd., Hackensack, NJ, 2005.

[5] A.G. Landers, T.B. Brill, Pressure-Temperature Dependence of the beta-delta Polymorph Interconversion In Octahydro-1,3,5,7-tetranitro-1,3,5,7-tetrazocine, J. Phys. Chem., 84 (1980) 3573.

[6] B.L. Weeks, C.M. Ruddle, J.M. Zaug, D.J. Cook, Monitoring high-temperature solid-solid phase transition of HMX with atomic force microscopy, Ultramicroscopy, 93 (2002) 19.

[7] P.C. Hsu, M.R. DeHaven, M.A. McClelland, C.M. Tarver, S.K. Chidester, J.L. Maienschein, Characterization of damaged materials, in: 13th International Detonation Symposium, Norfolk, VA, 2006, pp. 617.

[8] H.H. Cady, Studies on the Polymorphs of HMX, in, Los Alamos National Laboratory, Los Alamos, NM, 1961.

[9] R.K. Weese, A.K. Burnham, Coefficient of Thermal Expansion of the Beta and Delta Polymorphs of HMX, Propellants, Explosives, Pyrotechnics, 30 (2005) 344.

[10] J.L. Maienschein, J.F. Wardell, M.R. DeHaven, C.K. Black, Deflagration of HMX-Based Explosives at High Temperatures and Pressures, Propellants, Explosives, Pyrotechnics, 29 (2004) 287.

[11] P.A. Urtiew, J.W. Forbes, C.M. Tarver, K.S. Vandersall, F. Garcia, D.W. Greenwood, P.C. Hsu, J.L. Maienschein, Shock sensitivity of LX-04 containing delta phase HMX at elevated temperatures, in: APS National Meeting, Portland, OR, 2003, pp. 1.

[12] P.C. Hsu, P.C. Souers, S.K. Chidester, J. Alvarez, M.R. DeHaven, R. Garza, P. Harwood, J.L. Maienschein, Detonation measurements on damaged LX-04, Propellants, Explosives, Pyrotechnics, 32 (2007) 509.

[13] P.C. Hsu, M.R. DeHaven, M.A. McClelland, J.L. Maienschein, Thermal damage on LX-04 mock material and gas permeability assessment, Propellants, Explosives, Pyrotechnics, 31 (2006) 56.

[14] H.L. Friedman, Kinetics of thermal degradation of char-forming plastics from thermogravimetry. Application fo a phenolic plastic, J. of Polymer Sci. Part C, 6 (1964) 183.

[15] A.K. Burnham, R.L. Braun, Global Kinetic Analysis of Complex Materials, Energy and Fuels, 13 (1999) 1.

[16] A.K. Burnham, R.K. Weese, A.P. Wemhoff, J.L. Maienschein, A Historical and Current Perspective on Predicting Thermal Cookoff Behavior, Journal of Thermal Analysis, 89 (2007) 407.

[17] T.B. Brill, P.E. Gongwer, G.K. Williams, Thermal Decomposition of Energetic Materials. 66. Kinetic Compensation Effects in HMX, RDX, and NTO, J. Phys. Chem., 98 (1994) 12242.

[18] R. Behrens Jr., S.B. Margolis, M.L. Hobbs, A zero-dimensional model of experimental thermal decomposition of HMX, in: 11th International Detonation Symposium, Office of Naval Research, Snowmass, CO, 1998, pp. 533. 
[19] AKTS Thermokinetics, in, Advanced Kinetics and Technology Solutions, http://www.akts.com., Siders, Switzerland, 2009.

[20] R.L. Braun, A.K. Burnham, Kinetics05, in, The Regents of the University of California, Livermore, CA, 2006.

[21] L. Smilowitz, B.F. Henson, M. Greenfield, A. Sas, B.W. Asay, P.M. Dickson, On the nucleation mechanism of the beta-delta phase transitino in the energetic mnitramine octahydro-1,3,5,7-tetranitro-1,3,5,7-tetrazocine, J. of Chem. Phys., 121 (2004) 5550-5552.

[22] T. Hatakeyama, F.X. Quinn, Thermal Analysis : fundamental and applications to polymer science, John Wiley and Sons, Chinchester, England, 1995.

[23] J.H. Flynn, Thermogravimetric Analysis and Differential Thermal Analysis, in: H.H.G. Jellinek (Ed.) Aspects of Degradation and Stabilization of Polymers, Elsevier Scientific, Amsterdam, The Netherlands, 1978, pp. 573 603.

[24] A.K. Burnham, R.K. Weese, Kinetics of thermal degradation of explosive binders Viton A, Estane, and Kel F, Thermochimica Acta, 426 (2005) 85-92.

[25] T. Kovacic, Z. Mrklic, The kinetic parameters for the evaporation of plasticizers from plasticized poly(vinly chloride), Thermocheimica Acta, 381 (2002) 49-60.

[26] P.C. Hsu, P.C. Souers, M.R. DeHaven, R. Garza, J. Alvarez, J.L. Maienschein, Characterization of ThermallyDamaged LX-17, J. of Thermal Analy. and Calor., 93 (2008) 311. 